\title{
How do Economic Evaluations Inform Health Policy Decisions for Treatment and Prevention in Canada and the United States?
}

\author{
Don Husereau • Anthony J. Culyer • \\ Peter Neumann $\cdot$ Philip Jacobs
}

Published online: 15 October 2014

(c) Springer International Publishing Switzerland 2014

\begin{abstract}
Canadian and US health systems have often been characterized as having vastly different approaches to the financing and delivery of healthcare, with Canada portrayed as more reliant on rationing based on costs. In this article, we examine the similarities and differences between the two countries, the evolution and current role of health economic evaluation, and the roles played by health economists. We suggest both countries have similarly used economic evaluation to a limited extent for drug and immunization decisions, with variability in use more of a reflection of the incompleteness of both systems and their inherent institutional barriers rather than political ideology.
\end{abstract}

This article is part of the Topical Collection on The influence of Health Economists on Health Policy.

D. Husereau $(\bowtie) \cdot$ P. Jacobs

Institute of Health Economics, 1200, 10405 Jasper Avenue,

Edmonton, AB T5J 3N4, Canada

e-mail: dhusereau@ihe.ca

D. Husereau

Department of Epidemiology and Community Medicine, University of Ottawa, Ottawa, ON, Canada

\section{A. J. Culyer}

Institute of Health Policy, Management and Evaluation,

University of Toronto, Toronto, Canada

\author{
A. J. Culyer \\ Department of Economics and Related Studies, University of \\ York, York, UK \\ P. Neumann \\ Center for the Evaluation of Value and Risk in Health, Institute \\ for Clinical Research and Health Policy Studies, Tufts Medical \\ Center, Boston, MA, USA
}

\section{Key Points for Decision Makers}

Both the USA and Canada have used economic evaluation to similar degrees - the idea that costs are more largely considered in Canadian than in US public policy appears to be a myth.

Even when it has been used, economic evaluation has generally had little impact on decisions in each country; this has been observed for immunization and other decisions in the USA and public drug insurance decisions in Canada.

One explanation for its limited impact is a failure on the part of economic analysts to persuade the medical profession and administrators of its ethical fundamentals, and harm resulting from the superficial notion that costs are merely expenditures rather than opportunities for health that are forgone.

\section{Introduction}

Canadian and US health systems have often been characterized as having vastly different approaches to the financing and delivery of healthcare and to the use of costeffectiveness evidence [1-3]. At the extreme, Canada has been portrayed as having a UK-style reliance on rationing based on cost effectiveness, with its US counterparts willfully ignoring cost effectiveness [4]. However, closer examination reveals that the rhetoric often bears little resemblance to what is actually observed, and the influence of health economists and economic evaluation in both countries may share more similarities than differences. 
This article aims to provide a narrative overview of US and Canada health systems and how economic evaluation has been used. It provides opinions and reflection on the evolution and application of economic evaluations in decision making and the future implications of facilitators and barriers to their use.

\section{Comparing Health Systems}

In Canada, there are explicit statutory commitments in terms of access, universality of coverage, comprehensiveness for 'medically necessary' procedures, and portability of rights across provincial boundaries. The Canadian healthcare system has acquired an almost iconic status: as defining a set of values, and a national health system reflecting a consensus of social value that is distinctive from the system in the USA [2]. Despite this, there are striking similarities between Canadian and US healthcare systems, including largely decentralized financing and provision of services, lack of universal coverage for outpatient drugs (with employer-based private insurance and public drug insurance for those least able to afford care), and the private provision of hospital and medical care. A key difference is that, in the USA, the role of for-profit private provision is large, whereas in Canada the role of charities in provision is dominant.

In Canada and the USA, public outpatient drug pricing and reimbursement decisions are largely decentralized, as are population-based public health programs, such as immunization. Both Canada and the USA follow similar approaches to immunization, with the legislative mandate and delivery carried out by local health jurisdictions (states or provinces) and accompanying policy recommendations, regulations, and funding of research carried out by federal governments on the advice of expert committees. A significant difference is that delivery of immunization is carried out in Canada through its publicly funded health system whereas in the USA, federally funded services such as the Centers for Disease Control and Prevention Vaccine for Children Program may be delivered in either private or public health clinics $[5,6]$.

\section{Bridging Economic Evaluation to Health Policy}

\subsection{Pharmaceuticals}

The use of economic evaluation in both the Canada and the USA began with concerns about growth in healthcare expenditure from new interventions, with a focus on pharmaceuticals, in the early 1990s. Canada's first economic evaluation guidelines for formulary submissions were developed in Ontario in 1994. It was followed by national consensus guidance that is still used in a centralized review and recommendation process governed by public drug insurance programs (except Quebec). At the same time, US private managed care organizations began to issue guidance requiring a cost and impact analysis to support listing decisions [7]. Between 1979 and 1996, a total of 2,274 new cost-benefit analyses (CBA)/costeffectiveness analyses (CEAs) were published, of which $23 \%(525 / 2,274)$ focused on medications [8]. This was despite the fact that fewer than $10 \%$ of US national health expenditures (under $14 \%$ in Canada [9]) were devoted to drugs [8]. Today almost half of all published cost-utility analyses involve pharmaceuticals [10].

The publicly funded US Medicare program, which provides health insurance (including drugs) to some 40 million, mostly older, Americans, attempted to use cost effectiveness as a criterion for covering new medical technologies in the 1990s. This was eventually abandoned because of political and legal challenges [11]. Other US health technology assessment organizations also resisted using economic evaluations, along with some economists in the USA and Canada, seeing it cynically as a means of advancing commercial interests and a gizmo-besotted medical profession [12-14].

Although it would seem that Canadian public drug insurance programs have adopted policies that focus more heavily on costs and cost effectiveness than their US counterparts, an examination of past recommendations reveals that cost effectiveness is actually infrequently considered in either jurisdiction [15]. In Canada, where a maximum incremental cost per quality-adjusted life-year (QALY) ratio (ICER) threshold of $\$ 50,000 / \mathrm{QALY}$ has been proposed [16], positive recommendations for drugs with ICERs as high as \$CAD88,000/QALY have been given [17], while some in oncology have been valued as high as \$CAD144,000/QALY [18]. Setting de facto thresholds at such high levels has the potential to crowd out more cost-effective clinical interventions, causing a net loss of health in the community, and rendering methods of economic evaluation ineffective [19].

A similar situation can be seen in US private plans where, despite the promotion of economic evidence as a means to formulary listing for commercial plans, a survey of 91 private and public plans revealed that only $7 \%$ of respondents believe economic models submitted by manufacturers to have been influential in listing decisions [20]. Cost effectiveness has even been explicitly ruled out as a criterion for decision making by US public plans. However, there is some evidence that it plays a small role in coverage decisions [21]. Medicare Prescription Drug Plans, for example, have employed many techniques for restricting high-cost (and high-ICER) drugs, from tiered co-payments 
to prior authorization, and step therapy (using more costeffective drugs first) $[11,22]$. Despite this limited use of economic evaluation, it is evident that high-quality clinical evidence of clear (even if relatively small) benefit is a much stronger predictor of positive coverage decisions than cost effectiveness in both countries $[15,21]$.

\subsection{Immunization}

The World Health Organization (WHO) has recently suggested that country-specific recommendatory bodies for vaccines should systematically consider their economic impact (including the cost, cost effectiveness, and affordability of immunization) as an element in sustainable health system decision making for new vaccines [23, 24]. Consensus guidance for economic evaluation has also been developed [25]. These measures can be seen as a similar response to concerns about increased pharmaceutical spending in the early 1990s. In the past 10 years, new vaccines are less likely to be cost saving and are increasingly cost raising, due to higher prices and lower prevalence, morbidity, or transmissibility of the illnesses they are used to treat [26].

In both the USA and Canada, national immunization technical advisory groups (NITAGs) have been in place since 1964 [27, 28]. In 2008, the US NITAG, the Advisory Committee on Immunization Practices (ACIP), adopted a formal approach to incorporating economic evaluations into its recommendation processes. In Canada, review of vaccines is less centralized, with three national committees charged with this role; the National Advisory Committee on Immunization (NACI) has typically played the same role as its US ACIP counterpart, providing recommendations based on evidence of potential benefit and harm from use [28]. In 2004, after the development of a 2003 Canadian National Immunization Strategy and subsequent changes and consolidation of a federal role in Public Health, a new committee was established (the Canadian Immunization Committee) distinct from the national committee, with responsibility for planning and delivering immunization programs [29]. The strategy also led to the adoption of a new decision-making framework that included cost effectiveness along with provisions for price negotiation and bulk purchasing of vaccines across public programs [30].

Despite these modest efforts to incorporate economics into decision making, a 2011 review of immunization decision-making processes in Canada revealed that economic evaluations were still used rarely, despite the explicit processes for systematically incorporating them [31]. What has followed is an increasing recognition that the system is unsatisfactory: access to vaccines is variable due to inconsistent or overlapping processes and varies from one province to another; recommendations by the NACI may or may not consider cost effectiveness, and these may or may not be reimbursed in provincial jurisdictions [32]. This has created a call for increased harmonization [33], culminating in a 2013 workshop intended to improve the use of economic evaluation in a manner consistent with WHO recommendations [34].

In the USA, economic evaluation was first used by the ACIP in 2000, where positive recommendations for pneumococcal vaccine were based on an economic evaluation suggesting a societal net monetary benefit if priced below \$US46 per dose. The recommendations were accepted, and ultimately the price paid was \$US44.25 [35]. Cost effectiveness similarly influenced negative recommendations for routine human papillomavirus vaccination in males [36]. Although these early examples illustrate the use of economic information by the ACIP, they also led to concerns about how to interpret economic evidence [37], and the creation of an ad hoc Work Group on Economic Analysis tasked with developing guidance on the description and interpretation of economic information [27, 38]. A process of peer review and interpretation of economic evaluations has also been developed by working with a designated Centers for Disease Control and Prevention health economist, in recognition of the lack of formal training in economics by the immunization committee members, who have also expressed concern about the 'believability' of economic evaluation $[37,39]$. Despite some impact, costeffectiveness information has nonetheless also been ignored by the ACIP: a 2010 recommendation to provide quadrivalent meningococcal conjugate vaccine for adolescents was made despite cost-effectiveness evidence of its low value [36]. No formal assessment of the overall impact of economic evaluation on immunization decisions in the USA has been conducted.

These experiences suggest that economic evidence, when it is used for decision making, has (1) been mainly used in immunization decisions and limited other cases in the USA and public drug insurance decisions in Canada and (2) had a limited impact in each country.

\section{The Role of Health Economists and Economic Evaluation}

The origins of the use of economic evaluation in public policy can most certainly be traced to the USA, where resource-allocation decisions based on CBA were made in water resource management and defense contracts in a 1960s Johnson/Kennedy era of zero-based budgeting [40]. Engineers and operations researchers working in these fields facilitated the application of economic evaluation in healthcare resource-allocation decisions. This resulted in 
more than 400 published economic evaluations in healthcare appearing between 1966 and 1978 [40]. The promotion and use of economic evaluation in US immunization policy, supported by the US Centers for Disease Control and Prevention, a federal agency under the Department of Health and Human Services, can be seen as an extension of previous efforts in executive-level US federal policy making.

Toward the end of the 1970s, the economic evaluation of healthcare technologies became increasingly international, especially in academic circles in Canada, the USA, and the UK. It was further facilitated by an emerging consensus on the foundations of the approach - the principles and conduct of economic evaluation in healthcare [40-42], including the need to define decision problems clearly and conduct analyses of costs and consequences according to an explicit perspective. This period also saw a shift away from assigning monetary values to health outcomes and extended life through CBA, and an increased emphasis on the development and use of construct-valid measures of health gain and the non-monetary values embodied in them [40, 43]. Despite this emerging consensus on foundations, there continued to be long-standing and recognized challenges in its use, including a lack of consensus on analytic judgments (like appropriate outcomes and discount rates) and a failure to address distributional consequences formally [40-42].

The use of economic evaluation was also aided by a growing awareness in the clinical community of the need for consideration of the efficiency of clinical decisions in addition to clinical effectiveness. This was inspired, in part, by the British Archie Cochrane's 1972 work [44]. This explored how epidemiology could help clinicians understand which interventions were ineffective, or which effective interventions may be incorrectly used-what he called inefficiency in healthcare [44]. He recognized that, at administrative levels of public decision making, judgments of cost effectiveness have to be made, so his strong campaign for the randomized clinical trial had both a clinical motivation and a political one-the latter being his view that only effective medicines could be justifiably provided for free at public expense [44]. Cochrane's work relied on the emerging discipline of 'clinical epidemiology', a term invented by US physician Feinstein [45, 46], as a way of determining effectiveness.

The idea that costs as well as patient impact should both be considered in evidence-based decision making received its strongest boost in Canada's McMaster University, where clinical epidemiology at the bedside was promoted and the new discipline of 'evidence-based medicine' (EBM) was born. Explicit consideration of both costs and consequences of clinical decisions became part of the EBM ethos and led to new thinking [47], including new approaches to measuring and valuing health-related quality of life in clinical studies led in Canada by George Torrance at McMaster [48]. This ultimately led to the creation of the QALY, a term coined by US health economists Zeckhauser and Shepard [49]. The use and promotion of economic evaluation in Canada outpatient drug policy can be seen as an extension of EBM-based approaches. In Canada, public drug programs were originally led by EBM-trained hospital pharmacists who scaled up to the provincial level longstanding hospital-based managed care approaches to formulary listing.

\section{Reasons for Limited Impact}

Despite earnest attempts to incorporate considerations of economics more formally into decision making, they were, as has been seen, still not fully used, and, with some exceptions, commitment to their use is often nominal. At best, economic evaluation is an optional extra in both countries. The idea that costs are more largely considered in Canadian than in US public policy seems a myth. Overall, despite some uptake, the frequency of positive recommendations regarding low-value services suggests that economic evaluation still has little real direct impact in both countries. In many cases, it is simply not used explicitly at all.

Some reasons for this limited impact were suggested by Williams and Bryan [50]. They argued that the primary reasons are the acceptability and availability of economic evaluations. Acceptability is further sub-categorized as scientific/technical acceptability, structural/institutional acceptability, and ethical/political acceptability. Given the availability of economic evaluations for drug and immunization decisions, and a worldwide abundance of policyrelevant analyses of innumerable treatment and prevention interventions, it would appear that acceptability, rather than availability, is the main reason for lack of impact in both countries.

Our case examples from the USA and Canada illustrate the barriers of acceptability to use that still exist. In Canada, structural/institutional barriers, including differing capacities across provinces to use and assess economic evaluation, coupled with a lack of funding to coordinate its conduct or assessment, have (so far) hampered the routine use of economic evaluations in immunization. In the USA, the use of economic evaluation in Medicare has been restricted by ethical/political barriers to change that reflect in part Americans' cultural traditions that emphasize liberty, egalitarianism, anti-authoritarianism, and laissez-faire attitudes to private enterprise 
[51]. The recent use of cost effectiveness by Medicare to consider preventive services (not diagnostics or treatments) to its benefit package may reflect the reduction in barriers to use when important political (i.e., commercial) interests are less present. In those cases, economic evaluation appears to be used as a means to justify adding benefits rather than denying them.

While these barriers to acceptability seem to have been largely overcome in Canadian drug and US immunization decisions, the actual impact of their use is limited by skepticism in the medical profession as to the ethical acceptability of economic evaluation, and failures on the part of economic analysts to persuade clinicians of its ethical fundamentals. Cochrane himself contended that administrative decisions about new interventions are ultimately dependent on physicians. In both the USA and Canada, health system regulation of physicians' behavior and choices is accomplished through ethical standards of medical professionalism. In its current state, these standards have not promoted notions of opportunity cost as a means to ethical decision making. Rather, current EBMbased approaches recognize costs and cost effectiveness only after convincing evidence of clinical effectiveness $[15,52]$ and are consistent with the belief that it would be unethical to deny beneficial care to a patient due to considerations of cost.

Put another way, current EBM-based approaches to considering cost effectiveness support the misplaced notion that costs are merely expenditures rather than opportunities for generating health that have been forgone [53], and that the medical profession has an ethical obligation to insist on more spending in aggregate, even if $100 \%$ of the gross national product were spent on healthcare [54]; this unreasonable assertion is likely one not loudly refuted by commercial interests.

Administrators who have successfully introduced economic evaluation into decision making in both countries have in turn used EBM-based approaches, likely to ensure political palatability and consistency with current standards of medical professionalism. This has resulted in a superficial approach to using economic evaluation, where opportunity costs are seldom considered and costs are still viewed as expenditures [53]. Evidence of CEA as an optional extra can be seen in the governance structures of recommendatory committees. Unlike the UK National Institute for Health and Care Excellence (NICE) appraisal committees, for example, both the Canadian advisory body for drugs and the US advisory body for immunization have had no committee members with a formal economics background, instead relying on physicians or pharmacists who may (or may not have) have received training in economic evaluation.

\section{Concluding Thoughts}

Both the USA and Canada have used economic evaluation to similar degrees. Rather than acceptance or rejection of the use of economic evaluation on purely ideological grounds, the variable use of economic evaluation for treatment and prevention decisions in both countries appears to be largely a reflection of the barriers to acceptability in both systems. Notably, the Canadian system lacks sufficient structure to use economic evaluation routinely in immunization decisions, while political barriers reflecting manufacturers' interests in the USA have made economic evaluation unacceptable in drug-coverage decisions. When they have been used, a deeper examination reveals a limited impact that likely reflects ethical and political barriers to acceptability-both health systems have allowed physicians in their role as public policy decision makers to treat costs as additional expenditures rather than forgone opportunities for health.

The tragedy in viewing costs in this way is the potential for a substantially lower impact on the health and life expectancy of the populations of both countries than could be attained within the envelope of existing resources. As wrong as it is, failure to recognize lost opportunities for health may be understandable given the historical lack of true formal budgetary constraints or disincentives for exceeding spending limits. However, we should likely expect to see the limited impact of economic evaluation in both countries continue until we dismiss the erroneous notion that the uptake of low-value health services is harmless.

Acknowledgments The authors would like to acknowledge Scott Grosse who provided the initial suggestion to write the paper and also reviewed a previous draft.

Funding The authors volunteered their time to complete this work and declare no external sources of funding.

Conflict of interest disclosure All authors have read and completed conflict of interest disclosure forms at http://www.springer.com/cda/ content/document/cda_downloaddocument/COI_Form_-_Springer_ home_page.pdf?SGWID=0-0-45-1365465-p174503604 and declare: no support from any organization for the submitted work; Don Husereau and Peter Neumann declare having received consulting fees for providing health economic advice to medical device and pharmaceutical companies who might have an interest in the work; no other relationships or activities that could appear to have influenced the submitted work.

Author contributions All authors provided a substantial contribution to the design and interpretation of this piece, as well as writing and revising drafts based on comments received, and approving the final version. DH wrote the first draft after receiving agreement on an outline and description of the piece circulated to the other authors. DH revised and submitted subsequent drafts and is the guarantor. 


\section{References}

1. Reamy J. Health care in Canada: lessons for the United States. J Rural Health. 1991;7(3):210-21.

2. Naylor CD. The Canadian health care system: a model for American to emulate? Health Econ. 1992;1(1):19-37.

3. Globerman S, Hodges H, Vining A. Canadian and the United States' health care systems performance and governance: elements of convergence. Appl Health Econ Health Policy. 2002;1(2):75-88

4. Boyle T. Dr. Danielle Martin explains the virtues of our singlepayer system before a U.S. Senate subcommittee. The Toronto Star [Internet]. 2014. Available from: http://www.thestar.com/ life/health_wellness/2014/03/13/toronto_doctor_smacks_down us_senators_myths_about_canadian_health_care.html. Cited 25 Jun 2014.

5. CDC-VFC About the Program-Vaccines for Children Program-Vaccines [Internet]. Available from: http://www.cdc.gov/ vaccines/programs/vfc/about/. Cited 24 Jun 2014.

6. Hinman AR, Orenstein WA, Rodewald L. Financing immunizations in the United States. Clin Infect Dis. 2004;38(10):1440-6.

7. Luce BR. Pharmacoeconomics and managed care: methodologic and policy issues. Med Decis Mak. 1998;18(2 Suppl):S4-11.

8. Elixhauser A, Halpern M, Schmier J, Luce BR. Health care CBA and CEA from 1991 to 1996: an updated bibliography. Med Care. 1998;36(5 Suppl):MS1-9, MS18-147.

9. Canadian Institute for Health Information. National Health Expenditure Trends, 1975 to 2013 [Internet]. Ottawa: Canadian Institute for Health Information; 2013. Available from: https:// secure.cihi.ca/estore/productFamily.htm?locale $=$ en $\& p f=P F C 240$ 0\&lang=en2. Cited 1 Mar 2013.

10. Cost-Effectiveness Analysis Registry [Internet]. Available from: https://research.tufts-nemc.org/cear4/Home.aspx. Cited 6 Jul 2014.

11. Chambers JD, Neumann PJ, Buxton MJ. Does medicare have an implicit cost-effectiveness threshold? Med Decis Mak. 2010;30(4):E14-27.

12. Morgan S, Barer M, Evans R. Health economists meet the fourth tempter: drug dependency and scientific discourse. Health Econ. 2000;9(8):659-67.

13. Gerard K, Mooney G. QALY league tables: handle with care. Health Econ. 1993;2(1):59-64.

14. Leff B, Finucane TE. Gizmo idolatry. JAMA. 2008;299(15):1830-2.

15. Rocchi A, Miller E, Hopkins RB, Goeree R. Common drug review recommendations: an evidence base for expectations? Pharmacoeconomics. 2012;30(3):229-46.

16. Laupacis A, Feeny D, Detsky AS, Tugwell PX. How attractive does a new technology have to be to warrant adoption and utilization? Tentative guidelines for using clinical and economic evaluations. CMAJ. 1992;146(4):473-81.

17. Clement FM, Harris A, Li JJ, et al. Using effectiveness and costeffectiveness to make drug coverage decisions: a comparison of Britain, Australia, and Canada. JAMA. 2009;302(13):1437-43.

18. Chabot I, Rocchi A. How do cost-effectiveness analyses inform reimbursement decisions for oncology medicines in Canada? The example of sunitinib for first-line treatment of metastatic renal cell carcinoma. Value Health. 2010;13(6):837-45.

19. Paulden M, O'Mahony JF, Culyer AJ, McCabe C. Some inconsistencies in NICE's consideration of social values. Pharmacoeconomics. 2014;22:1-11.

20. EMD Serono Specialty Digest, 10th ed [Internet]. 2014. Available from: http://specialtydigest.emdserono.com/Archives.aspx. Cited 24 Jun 2014.

21. Chambers JD, Morris S, Neumann PJ, Buxton MJ. Factors predicting medicare national coverage: an empirical analysis. Med Care. 2012;50(3):249-56.
22. Neumann PJ, Lin P-J, Greenberg D, Berger M, Teutsch S, Mansley E, et al. Do drug formulary policies reflect evidence of value? Am J Manag Care. 2006;12(1):30-6.

23. Duclos P. National Immunization Technical Advisory Groups (NITAGs): guidance for their establishment and strengthening. Vaccine. 2010;19(28 Suppl 1):A18-25.

24. WHO | Global Immunization Vision and Strategy [Internet]. WHO. Available from: http://www.who.int/immunization/givs/ en/. Cited 19 Feb 2014.

25. Walker DG, Hutubessy R, Beutels P. WHO Guide for standardisation of economic evaluations of immunization programmes. Vaccine. 2010;28(11):2356-9.

26. Jacobs P. Are economic evaluations an important tool in vaccine policy decisions? Expert Rev Pharmacoecon Outcomes Res. 2011;11(5):507-11.

27. Smith JC. The structure, role, and procedures of the U.S. Advisory Committee on Immunization Practices (ACIP). Vaccine. 2010;28:A68-75.

28. Ismail SJ, Langley JM, Harris TM, Warshawsky BF, Desai S, FarhangMehr M. Canada's National Advisory Committee on Immunization (NACI): evidence-based decision-making on vaccines and immunization. Vaccine. 2010;19(28 Suppl 1):A58-63.

29. Government of Canada PHA of C. National Immunization Strategy (NIS) - Public Health Agency of Canada [Internet]. 2010. Available from: http://www.phac-aspc.gc.ca/im/nis-sni/ index-eng.php. Cited 19 Feb 2014.

30. Erickson LJ, De Wals P, Farand L. An analytical framework for immunization programs in Canada. Vaccine. 2005; 23(19):2470-6.

31. Government of Canada PHA of C. National Advisory Committee on Immunization (NACI)-Immunization \& Vaccines-Public Health Agency of Canada [Internet]. 2012. Available from: http:// www.phac-aspc.gc.ca/naci-ccni/sum-res/feb-fev-2011-eng.php. Cited 19 Feb 2014.

32. Scheifele DW, Ward BJ, Halperin SA, McNeil SA, Crowcroft NS, Bjornson G. Approved but non-funded vaccines: accessing individual protection. Vaccine. 2014;32(7):766-70.

33. MacDonald NE, Bortolussi R. A harmonized immunization schedule for Canada: a call to action. Paediatr Child Health. 2011;16(1):29.

34. Langley J, Krahn MD, Husereau DR, Spika J, Fisman D, Chit A, et al. Incorporating economic evaluation into immunization decision making in Canada, a workshop. Expert Rev Vaccines. 2014:1-6.

35. Pizzi L. Economic evaluation in U.S. health care: principles and applications. Jones \& Bartlett Learning, Burlington; 2006. 203 p.

36. Kim JJ. The role of cost-effectiveness in U.S. Vaccination policy. N Engl J Med. 2011;365(19):1760-1.

37. Dempsey AF, Cowan AE, Stokley S, Messonnier M, Clark SJ, Davis MM. The role of economic information in decision-making by the Advisory Committee on Immunization Practices. Vaccine. 2008;26(42):5389-92.

38. Ahmed F, Temte JL, Campos-Outcalt D, Schünemann HJ, ACIP Evidence Based Recommendations Work Group (EBRWG). Methods for developing evidence-based recommendations by the Advisory Committee on Immunization Practices (ACIP) of the U.S. Centers for Disease Control and Prevention (CDC). Vaccine. 2011;29(49):9171-6.

39. CDC-ACIP - guidance for health economics studies presented to the ACIP-vaccines [Internet]. Available from: http://www.cdc. gov/vaccines/acip/committee/guidance/economic-studies.html. Cited 25 Jun 2014.

40. United States. Congress. Office of Technology Assessment. The implications of cost-effectiveness analysis of medical technology [Internet]. Washington, D.C.: Congress of the United States, Office of Technology Assessment: For sale by the Supt. of Docs., 
U.S. G.P.O.; 1980. 238 p. Available from: http://archive.org/ details/implicationsofco00unit_2. Cited 22 Jun 2014.

41. Weinstein MC, Stason WB. Foundations of cost-effectiveness analysis for health and medical practices. $\mathrm{N}$ Engl $\mathrm{J}$ Med. 1977;296(13):716-21.

42. Drummond MF. Principles of economic appraisal in health care. Oxford: Oxford University Press; 1980. 148 p.

43. Culyer AJ. The normative economics of health care finance and provision. Oxf Rev Econ Policy. 1989;5(1):34-58.

44. Cochrane AL. Effectiveness \& efficiency: random reflections on health services. London: CRC Press; 1999.

45. Feinstein AR. Clinical epidemiology I. The populational experiments of nature and of man in human illness. Ann Intern Med. 1968;69(4):807-20.

46. Sackett DL. Clinical epidemiology. Am J Epidemiol. 1969;89(2): $125-8$.

47. Guyatt G, Drummond M, Feeny D, Tugwell P, Stoddart G, Haynes RB, et al. Guidelines for the clinical and economic evaluation of health care technologies. Soc Sci Med. 1986;22(4): 393-408.
48. Torrance GW, Thomas WH, Sackett DL. A utility maximization model for evaluation of health care programs. Health Serv Res. 1972;7(2):118-33.

49. Zeckhauser R, Shepard D. Where now for saving lives? Law Contemp Probl. 1976;40(4):5-45.

50. Williams I, Bryan S. Understanding the limited impact of economic evaluation in health care resource allocation: a conceptual framework. Health Policy. 2007;80(1):135-43.

51. Neumann PJ. American exceptionalism and American health care: Implications for the U.S. debate on cost-effectiveness analysis. [Internet]. Office of Health Economics; 2009. Available from: http://www.ohe.org/publications/article/american-exceptionalismand-american-health-care-31.cfm.

52. PausJenssen AM, Singer PA, Detsky AS. Ontario's formulary committee: how recommendations are made. Pharmacoeconomics. 2003;21(4):285-94.

53. Williams A. Health economics: the end of clinical freedom? BMJ. 1988;297(6657):1183-6.

54. Elhauge E. The limited regulatory potential of medical technology assessment. Va Law Rev. 1996;82(8):1525-622. 